Article

\title{
Comparative Analysis of Polymer Composites Produced by FFF and PJM 3D Printing and Electrospinning Technologies for Possible Filter Applications
}

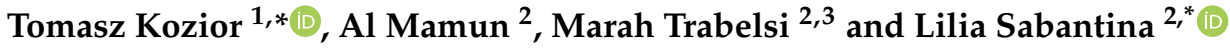 \\ 1 Faculty of Mechatronics and Mechanical Engineering, Kielce University of Technology, 25-314 Kielce, Poland \\ 2 Junior Research Group "Nanomaterials", Faculty of Engineering and Mathematics, Bielefeld University of \\ Applied Sciences, 33619 Bielefeld, Germany; al.mamun@fh-bielefeld.de \\ 3 Ecole Nationale d'Ingénieurs de Sfax, Sfax 3038, Tunisia; marah.trabelsi@enis.tn \\ * Correspondence: tkozior@tu.kielce.pl (T.K.); lilia.sabantina@fh-bielefeld.de (L.S.)
}

check for updates

Citation: Kozior, T.; Mamun, A.;

Trabelsi, M.; Sabantina, L.

Comparative Analysis of Polymer Composites Produced by FFF and PJM 3D Printing and Electrospinning

Technologies for Possible Filter

Applications. Coatings 2022, 12, 48.

https://doi.org/10.3390/

coatings 12010048

Academic Editor: Philippe Evon

Received: 27 November 2021

Accepted: 19 December 2021

Published: 1 January 2022

Publisher's Note: MDPI stays neutral with regard to jurisdictional claims in published maps and institutional affiliations.

Copyright: (c) 2022 by the authors. Licensee MDPI, Basel, Switzerland. This article is an open access article distributed under the terms and conditions of the Creative Commons Attribution (CC BY) license (https:// creativecommons.org/licenses/by/ $4.0 /)$.

\begin{abstract}
Three-dimensional printing technologies are mainly used to build objects with complex shapes and geometry, largely prototypes, and thanks to the possibility of building very thin layers of material with small pores, electrospinning technology allows for the creation of structures with filtration properties, in particular very small particles. The combination of these technologies creates new possibilities for building complex-shape composites that have not been comprehensively tested so far. The article describes the results of research on composites manufactured by combining samples prepared with two 3D printing technologies, Fused Filament Fabrication (FFF) and Photo-Curing of Liquid Polymer Resins (PJM) in combination with electrospinning (ES) technology. The surface morphology of composites manufactured from biocompatible materials was investigated using confocal laser scanning microscopy (CLSM) and contact angle measurements, and chemical composition analysis was studied using Fourier transform infrared spectroscopy (FTIR). This approach to creating composites appears to be an alternative to developing research for filtration applications. The article presents basic research illustrating the quality of composites produced by combining two unconventional technologies: 3D printing and electrospinning (ES). The analysis of the research results showed clear differences in the structure of composites produced with the use of various 3D printing technologies. The CLSM analysis showed a much better orientation of the fibers in the MED610 + PAN/gelatin composite, and the measurement of the contact angle and its indirect interpretation also for this composite allows for the conclusion that it will be characterized by a higher value of adhesion force. Moreover, such composites could be used in the future for the construction of filtering devices and in medical applications.
\end{abstract}

Keywords: quality; electrospinning; 3D printing; PJM; FFF; bio-materials; filtering

\section{Introduction}

The production of complex objects using conventional technologies requires the use of numerous technological processes and a large number of tools (injection molds, casting molds, dies, and cutting tools) [1] and thus the production of objects becomes timeconsuming. The use of 3D printing technology to produce complex objects, e.g., freeform objects [2], especially prototypes, in the era of industrial transformation 4.0, is a natural choice and fits perfectly into the realities of such issues as lean manufacturing and LPPD (lean process and product development) [3], where the main objective is to produce structures with a minimum weight and maximum fulfillment of product quality requirements [4] while maintaining an optimal manufacturing process. These technologies are successfully used wherever the time of product implementation is a key competitive parameter. Unconventional technologies include 3D printing, but also electrospinning, electro-erosion, electrochemical, laser, and ultrasonic processing and modern coating methods [5-7]. 
Due to the necessity of reducing the mass of the manufactured objects or increasing the strength and utility properties, composite materials manufactured of plastics are increasingly used in industrial applications. In the case of conventional technologies, there are known polymeric materials with additives of carbon and glass fibers, with molybdenum disulfide, with additives improving lubricating properties, etc. [8]. Three dimensional printing technologies also have some possibilities of using composite materials $[9,10]$, especially technologies such as Selective Laser Sintering-SLS, Fused Filament Fabrication-FFF, also commercially known as Fused Deposition Modeling-FDM ${ }^{\circledR}[11]$.

It seems that the SLS technology is well suited for manufacturing objects from composite materials, while the FFF technology is more appropriate for creating objects that are only made after combining with new material, e.g., using electrospinning technology. In many applications, however, the use of a composite material alone is not sufficient in order to achieve appropriate properties. The use of a composite material may increase strength and wear resistance, for example tribological [12] or rheological [13,14], but it does not necessarily provide the required properties, such as filtration.

An interesting solution may be a combination of two technologies, for example 3D printing and electrospinning $[15,16]$, or 3D printing and textile object $[17,18]$. The combination of $3 \mathrm{D}$ printing and electrospinning allows for the production of objects with very complex geometric shapes and high strength, and thanks to the use of electrospinning technology and nanofibers, such objects can exhibit filtration properties. The production of objects from biocompatible materials using 3D printing and electrospinning opens up new possibilities in medicine, e.g., in the field of implantology, where the use of 3D printing is increasing. In addition, 3D printing of metals, in particular, is used because of their high mechanical properties, as they are far more durable than human bones. By using electrospinning technology, the functional properties of the 3D objects produced can be improved and new properties can be added.

The use of 3D printing is very widespread and concerns such industries as rapid prototyping, foundry [19], injection molding, architecture, medicine [20], aviation, automotive [21], food, and flexible (lean) production series. The most important 3D printing technologies include SLS (Selective Laser Sintering), SLM (Selective Laser Melting), FFF (Fused Filament Fabrication), SLA (Stereolithography), Photo-Curing Technologies: PJM (polyjet matrix), PJ (polyjet), DoDjet (Drop on Demand Jetting Technology), and MJP (multijet). Due to the low initial cost of the machines with FFF-technology in contrast to other 3D printing technologies such as Selective Laser Sintering (SLS) or Selective Laser Melting (SLM), FFF technology includes the advantages of very low material costs, easy handling, and a wide range of materials for the production of composite materials. When choosing the combination of 3D printing and electrospinning technology, FFF technology seems to offer the optimal solution due to the above-mentioned advantages. With this FFFtechnology, many interesting materials are available such as acrylonitrile butadiene styrene (ABS), poly(lactic acid) (PLA), PLA + carbon fiber, PET, Nylon, TPU, and PC, which are also reinforced with additives. Although the FFF technology can use composite materials, they cannot be easily modified independently, as is the case with SLS technology. In FFF, these materials can be treated both thermally and chemically, which improves the quality of the manufactured objects $[22,23]$. PLA material, being the cheapest and the most important due to its very good functional features, is a good solution for the construction of prototypes with filtration properties [24] combined with electrospinning technology. Comparing both technologies, it can be clearly stated that the big disadvantage of the PJM technology is the high cost of the model material (liquid resin) compared to the filament in the FDM technology, which costs only a few dollars per kilogram. However, its great advantage is its high manufacturing accuracy, especially in the $Z$ axis, due to the very small thickness of the layer being built (as small as $16 \mu \mathrm{m}$ ). Many studies have aimed at determining the influence of technological parameters on the properties of the manufactured objects [25-30] and the influence of measurement methods on the reliability of the test results [31]. 
The electrospinning technique is the most widely used, simplest, and most costeffective method to produce nanofibers from a wide range of bio-based and synthetic polymers as well as admixtures, such as particles [24].

For nanofiber fabrication, it is possible to use nontoxic or low-toxicity solvents such as dimethyl sulfoxide (DMSO) and polymers soluble in it $[32,33]$. The polymer polyacrylonitrile (PAN) is often used for nanofiber mat fabrication because it can be spun from DMSO, has no cell toxicity and is water resistant [34,35]. Moreover, by adding other polymers, such as gelatin or magnetic particles to the PAN solution, nanofiber mats for defined purposes are easily prepared by simply adding these compounds to the polymer electrospinning solution [36,37]. PAN nanofiber mats are flexible and become even more flexible when wet, and can be easily stretched and draped without any problems [38]. In addition, PAN is often used for the production of carbon material due to its high carbon yield [39]. Gelatin is a biobased polymer which is often used in biotechnological fields due to its biocompatibility and is also used for the production of nanofibers.

With 3D printing technology, the available range of materials is wide, which allows for selection of the appropriate material depending on the field of application, for example in medicine. As a result, these technologies can be used, among others, as medical dressings, scaffolding in tissue engineering or controlled drug delivery systems. Despite the long time that has passed since the first papers on electrospinning technology were published, they are still in the testing phase due to the production of new electrospinning devices and new materials with improved properties. Research work largely focuses on the study of new materials [32,37,40], including composites [41], and the properties [42] of the produced objects, such as filtration, as well as composites obtained by combining electrospinning technology and, for example, 3D printing. Moreover, the electrospinning technology can also be used for the production of nanofibers and in the construction of composite materials, e.g., by conventional methods [43].

Our previous research works in this field $[15,16]$ focused on composites using combination of FFF technology and needle-free electrospinning technology. The novelty of this study is that in the present work, two technologies were used to produce composites, namely PJM and FFF 3D printing technologies in combination with needle-based electrospinning technology for use in filter applications in medical filed, and the variable technological parameters were studied in more detail. For use in filtering areas, final composite consists of 3D printed structure that incorporates the robustness and thus supports the fine and fragile nanofiber mats, which has excellent filtering properties and requires mechanical protection. The printing direction in relation to the XZ build platform and the filling level with the model material were analyzed. In addition, 3D objects were fabricated from two biocompatible materials such as PLA and MED610, which show a high potential for use in the medical industry due to their biocompatibility. These 3D objects were electrospun using two different types of nanofiber mats, such as pure polyacrylonitrile (PAN) nanofibers and a combination of PAN and gelatin. PAN nanofiber mats are often used in medical and filter areas and the PAN polymer is valued for its water-resistant properties. In addition, it should be mentioned that the nanofiber mats were produced using the low-toxicity solvent dimethyl sulfoxide (DMSO) and there are few studies in this area, because mostly highly toxic solvents such as dimethylacetamide (DMAc) and dimethylformamid (DMF) are widely used in the production of nanofiber mats. The combination of 3D materials such as PLA and MED610 with nanofibers with PAN and gelatin show a high potential for effective application in the medical industry for filtration applications. The fabrication of such novel composite models by combining two different technologies (3D printing and electrospinning) is important for many reasons, but the most important is the one concerning the geometrical possibilities of the created models. In addition, the use of these two methods and indirect assessment of the diameter of the fibers, their orientation, and contact angle measurements will allow the initial assessment of the quality of the produced composites also in the context of filtration, where the distribution of the fibers, their diameter, and directionality depend on the material, 3D printing technology and 
parameters and material in the electrospinning technology.. This is why the purpose of this research is to conduct a preliminary comparative analysis. In the case of 3D printing, the use of biodegradable PLA material in FFF technology and PJM technology allows the use of MED610 material with biocompatible properties, which are beneficial for some medical applications. The preliminary research results presented below require further research, but they can provide a valid basis for further, expanded research that considers the body's response to such composites.

\section{Materials and Methods}

The test samples were designed in Solidworks re-SolidWorks (Dassault Systèmes SolidWorks Corp., Waltham, MA, USA), in the shape of a rectangular prism with the dimensions of $50 \times 50 \times 0.5 \mathrm{~mm}^{3}$. The SolidWorks objects were written as STL files (stereolithography language), mapping the objects as a mesh of triangles. The translation accuracy was in the so-called fine record mode, but in this case, due to the simplicity of the object, each form of notation maps the object in the same way, i.e., with 12 triangles. These designed objects were sent to internal 3D printer systems, manufactured using two 3D printing technologies-FFF [44] and PJM, and then removed from the platform and cleaned: FFF — manually, PJM-with water under pressure. After completing the printing process and cleaning, the objects were subjected to the electrospinning process, which, using high-voltage electrical discharges, applied a layer of material on a surface with the dimensions of $50 \times 50 \mathrm{~mm}^{2}$ (see Figure 1).

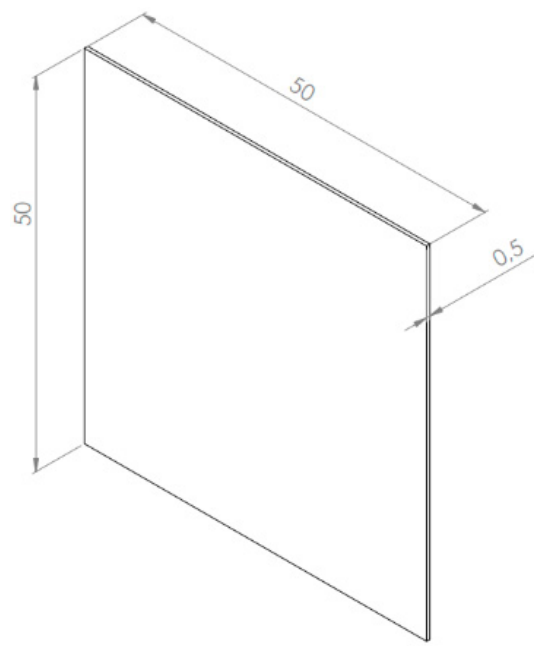

Figure 1. 3D CAD sample, dimensions in $\mathrm{mm}$.

\subsection{D printing Methods}

Two 3D printing machines with FFF and PJM technologies were used to build the objects and later coated with nanofibers. In the case of the photo-curing technology of liquid polymer resins-PJM (Objet Geometries Ltd., Rehovot, Israel), a Connex 350 machine by Object (currently Stratasys, Ltd., Eden Prairie, MN, USA) was used, and in the case of the Fused Filament Fabrication-FFF (also known as FDM) technology, the Makerbot Replicator 5th generation machine was used. In the FFF technology, polylactide (PLA) material (trade name-EASY PLA, Fiberlogy company, Poland) was used to build the samples, and in the PJM technology, the biocompatible material MED610 (Stratasys company, Ltd., Eden Prairie, MN, USA). MED610 material is a material that is approved for contact with the human skin for a period of 30 days and for contact with the mouth for $24 \mathrm{~h}$, making it very attractive in medicine, such as an element of medical devices, filtering masks, prototypes of orthoses, as well as in the field of dental interests, such as dental appliances [45]. MED610 has been evaluated and deemed acceptable for the following biological risk [45]: Cytotoxicity-EN ISO 10993-5: 2009 [46]; Irritation-EN ISO 10993-10: 2013 [46] Delayed-type hypersensitivity_EN ISO 10993-10: 2013 [46]; Genotoxicity_EN 
ISO 10993-3: 2014 [46]; Chemical characterization-EN ISO 10993-18: 2009 [46]; USP Plastic Class VI-USP $34<88>$ [47].

Table 1 and Figure 2 show the chemical composition of the materials used in the construction of samples with 3D printing technologies.

Table 1. Composition of MED610 material [45].

\begin{tabular}{ccc}
\hline & Information on Ingredients \\
\hline CAS\# & Component & Percent (\%) \\
\hline $5888-33-5$ & Isobornyl acrylate & $15-30$ \\
Proprietary & Acrylic monomer & $15-30$ \\
Proprietary & Urethane acrylate & $10-30$ \\
Proprietary & Acrylic monomer & $5-10 ; 10-15$ \\
Proprietary & Epoxy acrylate & $5-10 ; 10-15$ \\
Proprietary & Acrylate oligomer & $5-10 ; 10-15$ \\
Proprietary & Photoinitiator & $0.1-1 ; 1-2$ \\
\hline
\end{tabular}<smiles>CCOC(=O)C(C)C</smiles>

Figure 2. Structural model of PLA material [48].

The test specimens were manufactured in three predetermined orientations relative to the $0^{\circ}, 45^{\circ}$, and $90^{\circ}$ build platform. The overview of samples orientation on the build platform prepared for FFF process is shown in the Figure 3. Moreover, in the FFF technology, samples 1-9 (see Figure 3a) were manufactured with a layer thickness of $0.2 \mathrm{~mm}$, samples 10-18 (not shown here) with a layer thickness of $0.3 \mathrm{~mm}$ and both types with $95 \%$ filling, and samples 19-27 (see Figure $3 b$ ) with a layer thickness of $0.2 \mathrm{~mm}$ and a filling of $50 \%$.

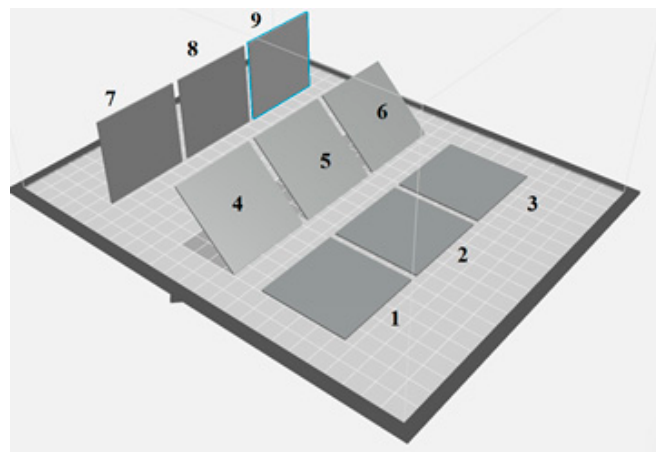

(a)

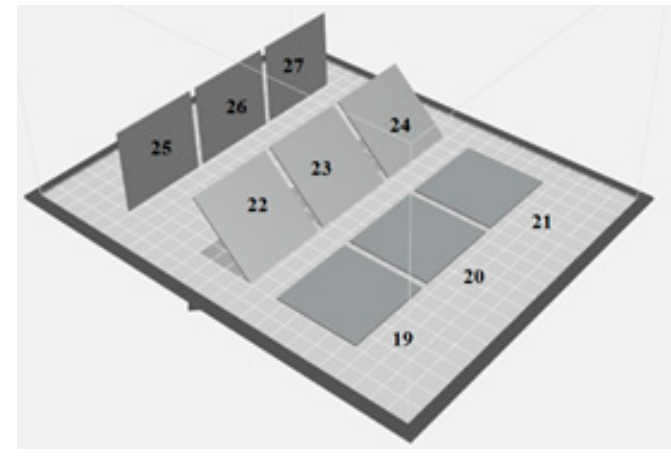

(b)

Figure 3. Overview of samples orientation on the build platform prepared for FFF process: (a) samples 1-9, (b) samples 19-27.

Samples in the PJM technology were manufactured in two variants: 28-36 (see Figure $4 \mathrm{a}$ ) with a layer thickness of $0.032 \mathrm{~mm}$, i.e., in the High Speed mode and $100 \%$ filling, and the samples 37-45 (see Figure 4b) were manufactured in the so-called High Quality mode with a set layer thickness of $0.016 \mathrm{~mm}$ and also $100 \%$ filling. A total of 45 samples were manufactured, but the total number of different types of samples is only 15, because three pieces of each type were made in order to statistically evaluate the repeatability of the measurement results, so there are no differences between samples 1, 2, and 3, and in subsequent batches after 3 pieces. Figures 3 and 4 show the location of samples on virtual platforms of working machines. 


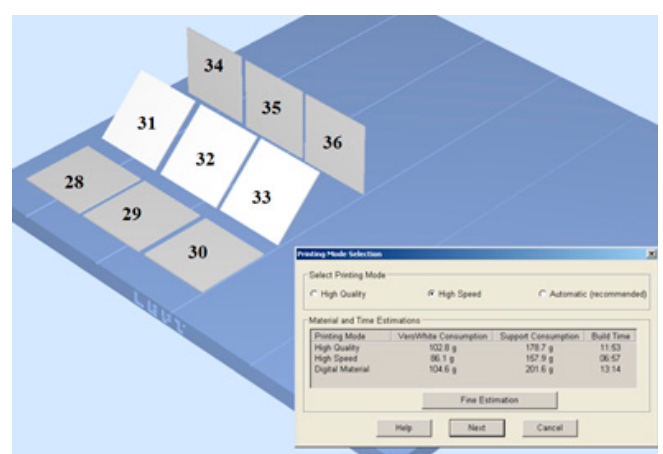

(a)

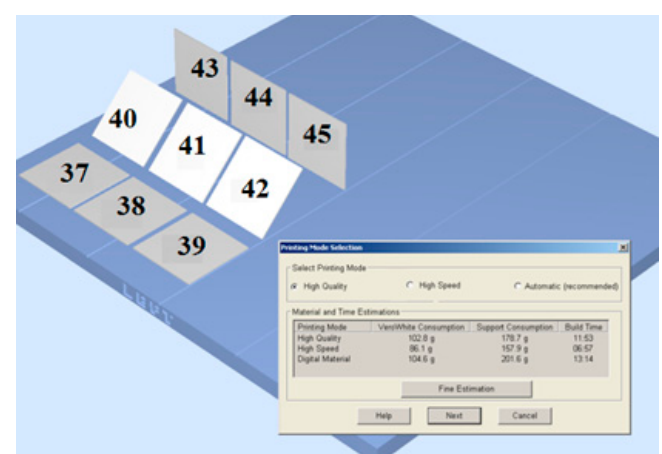

(b)

Figure 4. Overview of samples orientation on the build platform prepared for PJM process: (a) samples 28-36, (b) samples 37-45.

Figure 5a shows 3D-printed sample prepared from PLA using FFF technology and Figure $5 \mathrm{~b}$ shows the sample prepared from MED610 using PJM technology.

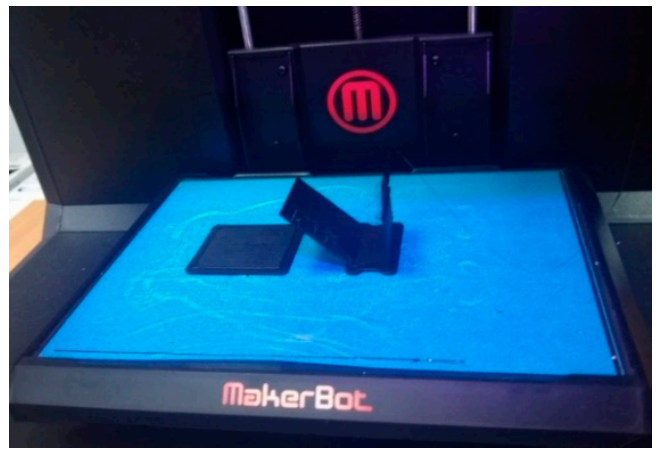

(a)

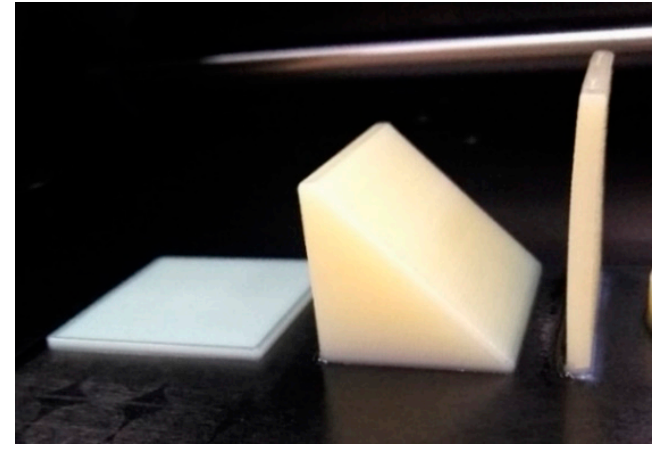

(b)

Figure 5. Overview of 3D printed samples: (a) 3D printed samples prepared from PLA by FFF technology and (b) from MED610 by PJM technology.

\subsection{Electrospinning}

The nanofibers were produced by the needle-based electrospinning machine (SpinboxBioinicia S.L., Paterna, Valencia, Spain) (see Figure 6).

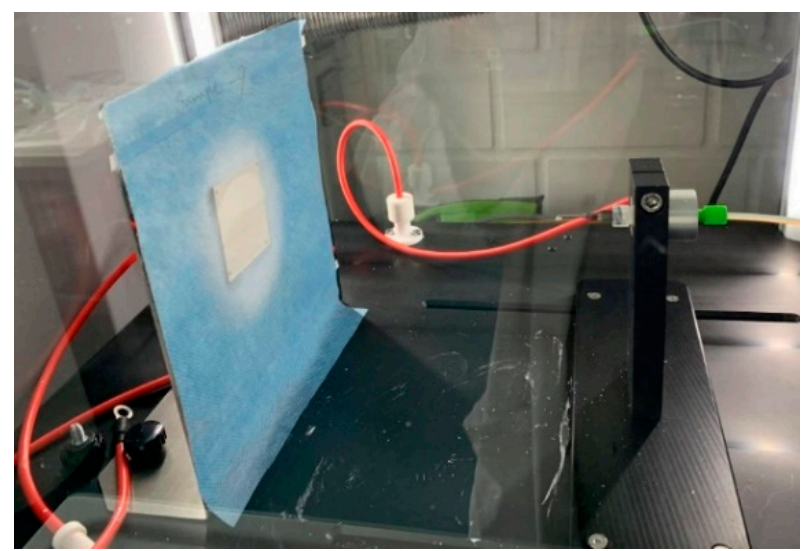

Figure 6. Electrospun 3D printed sample in the electrospinning device.

The applied spinning parameters in the manufacturing process were as follows: high voltage $8-18 \mathrm{kV}$, temperature in the chamber $20-23^{\circ} \mathrm{C}$, relative humidity in the chamber $35-40 \%$, a $20 \mathrm{~cm}$ distance from the needle tip to the nanofiber collector, and the flow rate of polymer solution $300-500 \mu \mathrm{L} / \mathrm{h}$. The polymer nanofibers were produced using an 
18-gauge needle (1.23 mm outer diameter). Spinning duration was approximately $15 \mathrm{~min}$, which was also used as 3D printing material on non-woven polypropylene (PP) substrates (Elmarco, Czech Republic). Polyacrylonitrile (PAN) (X-PAN, Dralon, Dormagen, Germany) polymer and dimethyl sulfoxide (DMSO, min 99.9\%, purchased from S3 Chemicals, Bad Oeynhausen, Germany) solvent were used for production of all nanofiber mats.

The polymer solutions were mixed by magnetic stirring for $2 \mathrm{~h}$ at room temperature. Two types of nanofiber mats were used based on polymer properties for biolog$\mathrm{ical} / \mathrm{medical} / \mathrm{chemical}$ purposes to create composites with biocompatible materials as composites for filtration applications (see Table 2). The first spinning solution is the mixture of $13 \%$ PAN and $87 \%$ DMSO. The second spinning solution contained $13 \%$ PAN and $8 \%$ gelatin powder (Abtei OP Pharma GmbH, Marienmünster, Germany) and 79\% DMSO.

Table 2. Overview of the 3D printed samples.

\begin{tabular}{ccc}
\hline 3D Printed Sample No. & 3D Material & Nanofiber Mats \\
\hline $1-6$ & PLA & PAN 13\%+ DMSO 87\% \\
$7-18$ & PLA & PAN 13\% + gelatin 8\% + DMSO 79\% \\
$19-27$ & PLA & PAN 13\% + gelatin 8\% + DMSO 79\% \\
$28-36$ & MED610 & PAN 13\% + gelatin 8\% + DMSO 79\% \\
$37-45$ & MED610 & PAN 13\% + gelatin 8\% + DMSO 79\% \\
\hline
\end{tabular}

The aim of this research was the preliminary assessment of polymer composites produced by 3D printing and electrospinning technologies in the application of filtering and medical purpose. For this purpose, several types of samples were selected for the comparative tests and are presented in Table 2.

The 3D printed objects were vertically attached and electrospun. Figure 7a shows PLA sample prepared using FFF and coated with PAN nanofiber mat and Figure $7 \mathrm{~b}$ shows MED610 sample prepared using PJM and coated with PAN/gelatin nanofiber mat.

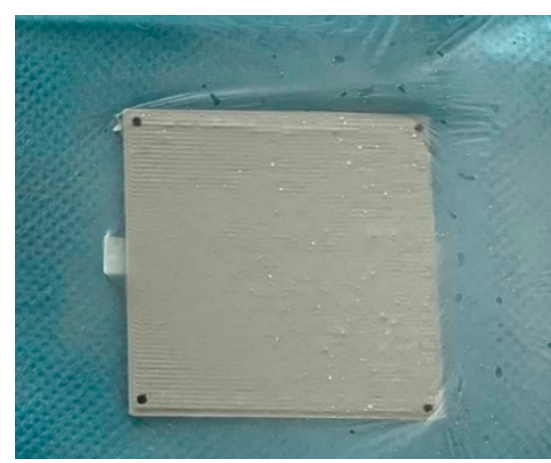

(a)

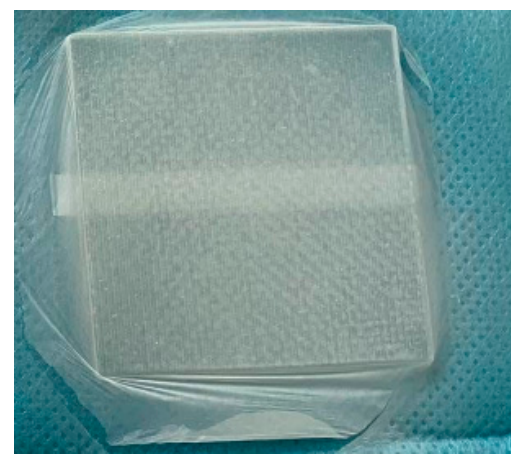

(b)

Figure 7. (a) Sample No. 3-prepared from PLA using FFF and coated with PAN nanofiber mat and (b) sample No. 29-prepared from MED610 using PJM and coated with PAN/gelatin nanofiber mat (b).

\subsection{Research Methods}

Fourier transform infrared spectroscopy (FTIR) is a tool that provides significant information about chemical bonding, molecular structures, and component miscibility. In this study, the chemical study was performed with an Excalibur 3100 fourier transform infrared spectroscope (FTIR) (Varian Inc., Palo Alto, CA, USA). The spectra were recorded between 4000 and $650 \mathrm{~cm}^{-1}$ frequency ranges.

The optical evaluation of the morphology of the samples was performed with the use of a confocal laser scanning microscope (CLSM) VK-8710 (Keyence, Osaka, Japan).

The water contact angle was measured using the contact angle goniometer OCA 15 Pro (Dataphysics, Filderstadt, Germany). The measurements were performed with $5 \mu \mathrm{L}$ water droplets at the inner surface of the polystyrene well plates in ambient conditions. 
Eight measurements were performed for each material. For contact angles below $90^{\circ}$, the surface is considered as hydrophilic. Contact angles greater than $90^{\circ}$ are considered as hydrophobic.

The diameters of the nanofibers were evaluated using the ImageJ 1.51j8 program.

\section{Results}

The results of testing are presented below. In Section 3.1, the analysis of fourier transform infrared spectroscopy is investigated. Then, the results of surface measurements are described using confocal laser scanning microscopy (CLSM) in Section 3.2. The analysis of the contact angle is presented in Section 3.3.

\subsection{FTIR Results}

FTIR was used to show that the nanofiber mats were electrospun onto the printed samples. Figure 8a shows electrospun PAN/gelatin nanofiber mats on PAN nanofiber mats on PLA and Figure 8b shows MED610 and PAN/gelatin nanofiber mats electrospun on MED610. The electrospun nanofiber mats on PLA and MED610 are advantageous for cell growth and also for numerous filter applications, which presents new manufacturing possibilities for medical applications, especially in implant production.

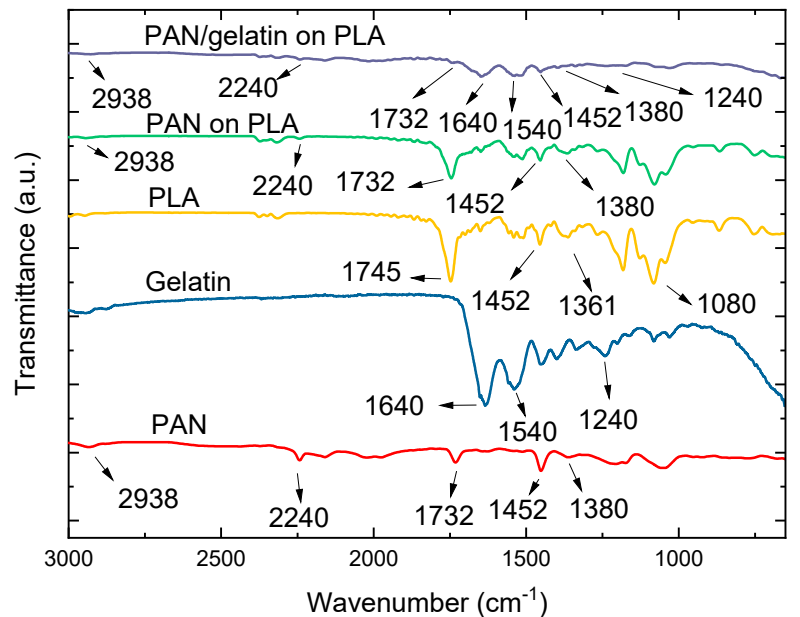

(a)

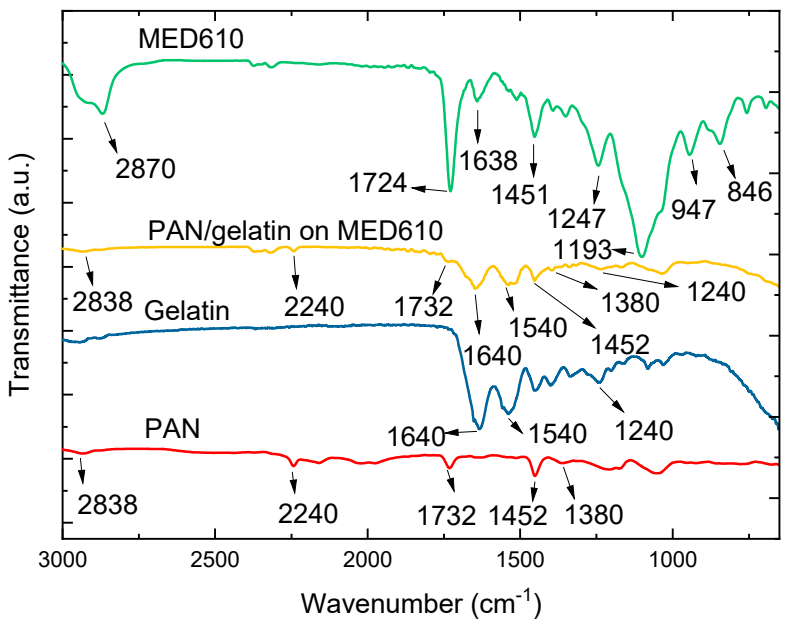

(b)

Figure 8. FTIR results: (a) PAN/gelatin nanofiber mats on PLA sample, PAN nanofiber mats on PLA sample, PLA sample without coating with nanofiber mat, pure gelatin, and PAN nanofiber mat; (b) MED610 sample without coating with nanofiber mat, PAN/gelatin nanofiber mats on MED610, pure gelatin, PAN nanofiber mat.

The overview of typical spectra of used materials can be seen in Table 3. In Figure $8 a, b$, typical and characteristic FTIR peaks of the materials used. In addition, these peaks are shown again in Table 3 for clarity. When looking at Figure 8a, it can be seen that some peaks occur continuously at the marked locations with a crossed-out line, and thus it is not easy to distinguish between the characteristic peaks for a specified material. However, some peaks, such as PLA of $1452 \mathrm{~cm}^{-1}$, also occur in PAN and can be seen in all three FTIR spectra (see Figure 8a). 
Table 3. Overview of the typical FTIR spectra of gelatin, PLA, PAN and MED610.

\begin{tabular}{|c|c|c|}
\hline Polymers & FTIR Spectra & Reference \\
\hline Gelatin & $\begin{array}{l}\text { Gelatin spectra bands: } \\
2700-3600 \mathrm{~cm}^{-1} \text { _amides A and B } \\
3400 \mathrm{~cm}^{-1} \text {-amide A } \\
1640,1540 \text { and } 1240 \mathrm{~cm}^{-1} \_\mathrm{C}=\mathrm{O} \text { stretching of amide I, N-H bending of } \\
\text { amide II and N-H bending of amide III } \\
900-1900 \mathrm{~cm}^{-1} \text {-amides I, II and III } \\
900 \mathrm{~cm}^{-1} \text {-amide IV } \\
700 \mathrm{~cm}^{-1} \text {-amide IV }\end{array}$ & {$[37,49,50]$} \\
\hline PLA & $\begin{array}{l}1745 \mathrm{~cm}^{-1}-\mathrm{C}=\mathrm{O} \text { group } \\
1452 \mathrm{~cm}^{-1}-\mathrm{CH} 3 \text { asymmetric group } \\
1361 \mathrm{~cm}^{-1}-\mathrm{CH} 3 \text { symmetric group } \\
1080 \mathrm{~cm}^{-1}-\mathrm{C}-\mathrm{O} \text { group } \\
695-760 \mathrm{~cm}^{-1} \text { and } 1740-1750 \mathrm{~cm}^{-1}-\mathrm{C}=\mathrm{O} \text { group }\end{array}$ & [51] \\
\hline PAN & $\begin{array}{l}2240 \mathrm{~cm}^{-1}-\mathrm{C} \equiv \mathrm{N} \text { nitrile stretching vibration mode } \\
1732 \mathrm{~cm}^{-1}-\text { carbonyl }(\mathrm{C}=\mathrm{O}) \text { stretching vibration mode } \\
2938,1452 \text { and } 1380 \mathrm{~cm}^{-1}-\mathrm{CH}_{2} \text { stretching vibrations }\end{array}$ & [52] \\
\hline MED610 & $\begin{array}{l}2870 \mathrm{~cm}^{-1}-\mathrm{C}-\mathrm{H} \text { stretching vibration mode } \\
1724 \mathrm{~cm}^{-1}-\mathrm{C}=\mathrm{O} \text { stretching vibration mode } \\
1247 \mathrm{~cm}^{-1}-\mathrm{C}-\mathrm{H} \text { stretching vibration mode } \\
1193 \mathrm{~cm}^{-1}-\mathrm{C}-\mathrm{O} \text { stretching vibration mode } \\
2870 \mathrm{~cm}^{-1} \\
1724 \mathrm{~cm}^{-1} \\
1638 \mathrm{~cm}^{-1} \\
1247 \mathrm{~cm}^{-1} \\
1193 \mathrm{~cm}^{-1} \\
846 \text { and } 947 \mathrm{~cm}^{-1}\end{array}$ & {$[53,54]$} \\
\hline
\end{tabular}

Looking at the Figure 8a, it becomes visible that the characteristic FTIR spectra of 1732, $1745,1452,1380$ and $1361 \mathrm{~cm}^{-1}$ occur in PLA, PAN/gelatin, and PAN nanofiber mats (see Table 3). At this point, it is not possible to say precisely that these peaks belong only to a particular material.

Moreover, it is assumed that 3D-printed PLA materials shine through the layer of nanofiber mat (see Figure 8a) and even the characteristic peak for PLA at $1080 \mathrm{~cm}^{-1}$ is also slightly visible for PAN/gelatin and PAN nanofiber mats.

When looking at Figure 8b, some peaks, such as $1724 \mathrm{~cm}^{-1}$ of MED610 and $1732 \mathrm{~cm}^{-1}$ of PAN/gelatin nanofiber mats, are in a narrow range and at this point overlap slightly. The peaks at $1638 \mathrm{~cm}^{-1}$ of MED610 and at $1640 \mathrm{~cm}^{-1}$ of PAN/gelatin nanofiber mat are in a narrow range, and the peaks at $1451 \mathrm{~cm}^{-1}$ of MED610 and at $1452 \mathrm{~cm}^{-1}$ of PAN/gelatin nanofiber mat are also in a narrow range and can be detected in the Figure 8 a by all three FTIR spectra.

\subsection{CLSM Results}

CLSM images of composites are depicted in Figures 9-14. Figure 9 shows the PAN nanofiber mats on PLA object. In addition, Figure 10 shows the surface of PLA object without nanofiber mats. Figure 11 presents the PAN/gelatin nanofiber mats on PLA object. In addition, Figure 12 shows the 3D printed side of PLA. Figure 13 presents CLSM images of the PAN/gelatin nanofiber mats MED610 object. In addition, Figure 14 shows the surface of MED610 object without nanofiber mat. 


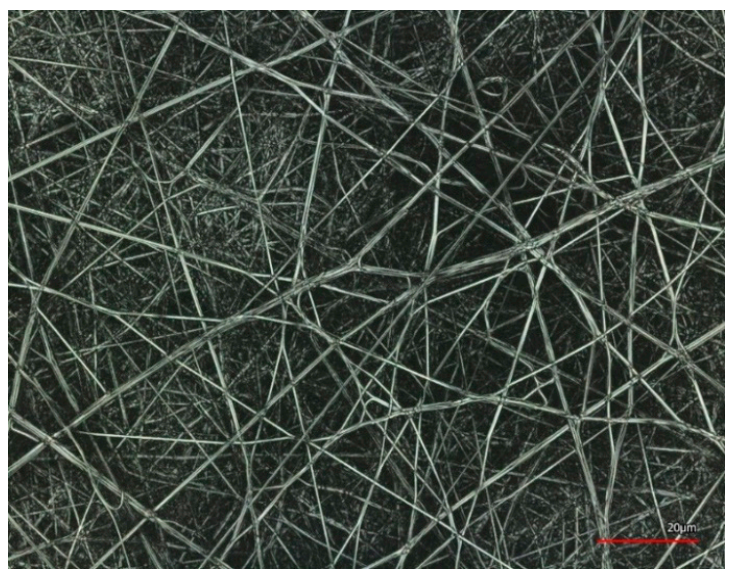

(a)

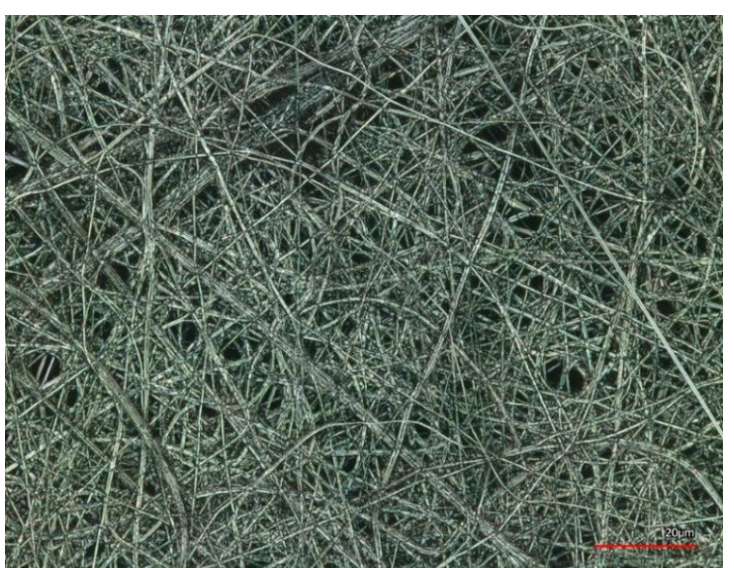

(b)

Figure 9. Confocal laser scanning microscope (CLSM) images of PAN nanofiber mats on PLA object. PLA object is covered with nanofibers and is not visible: (a) sample-1, (b) sample-2. Scale bars indicate $20 \mu \mathrm{m}$.

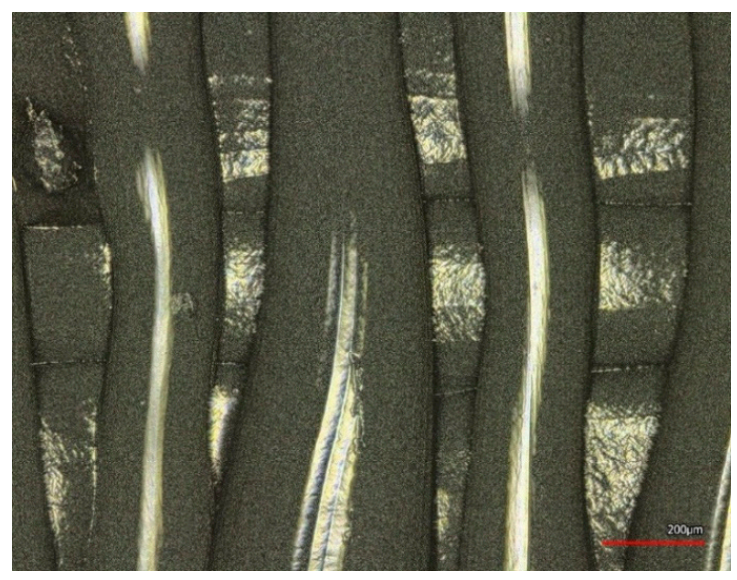

Figure 10. Confocal laser scanning microscope (CLSM) image of PLA object, sample-1. Scale bar indicates $200 \mu \mathrm{m}$.

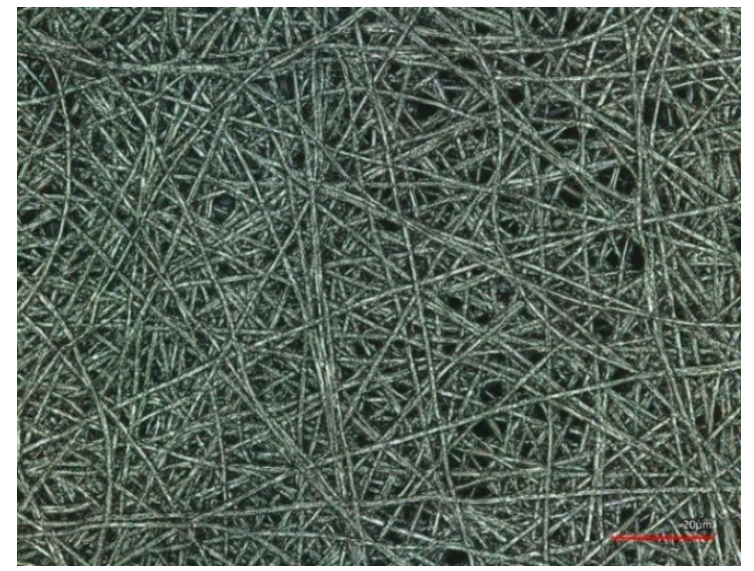

(a)

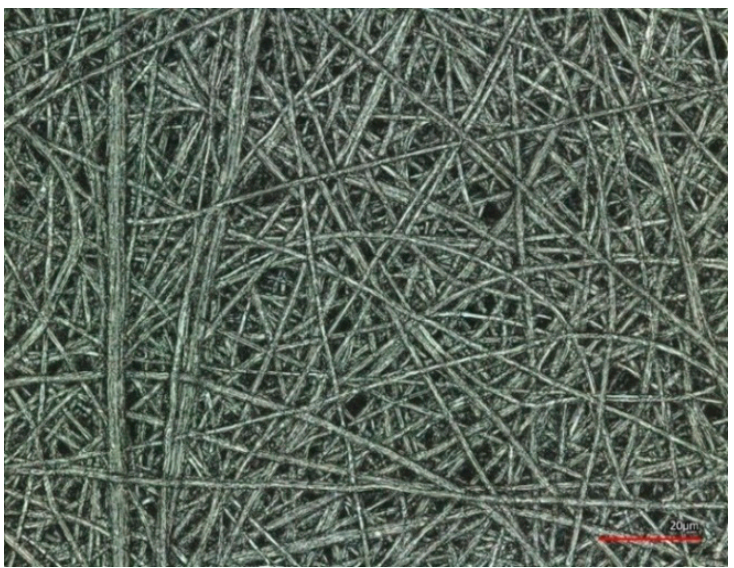

(b)

Figure 11. Confocal laser scanning microscope (CLSM) images of of PAN/gelatin nanofiber mats on PLA object. PLA object is covered with nanofibers and is not visible: (a) sample-7, (b) sample-8. Scale bars indicate $20 \mu \mathrm{m}$. 


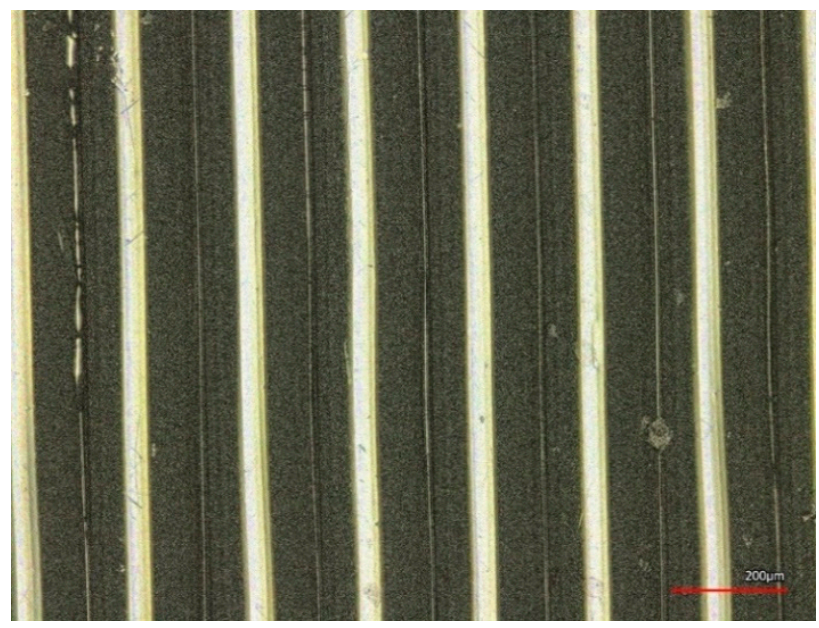

Figure 12. Confocal laser scanning microscope (CLSM) image of PLA object, sample-7. Scale bar indicates $200 \mu \mathrm{m}$.

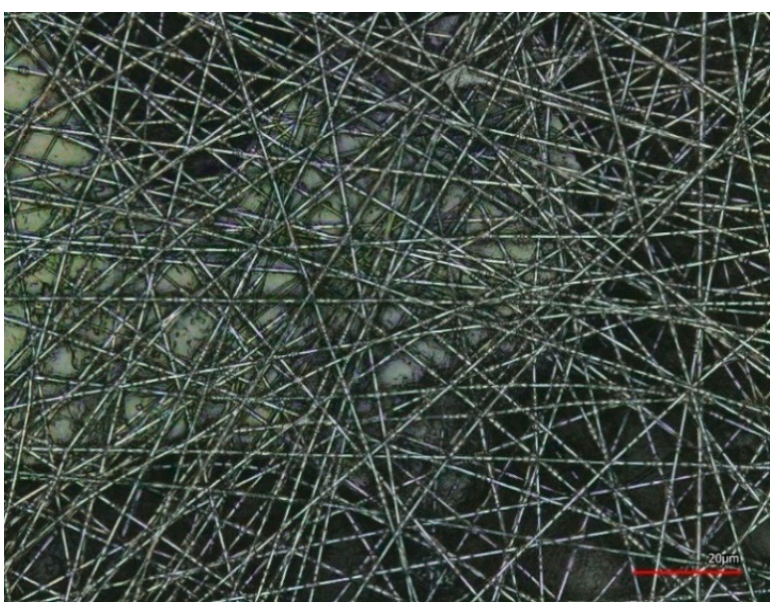

(a)

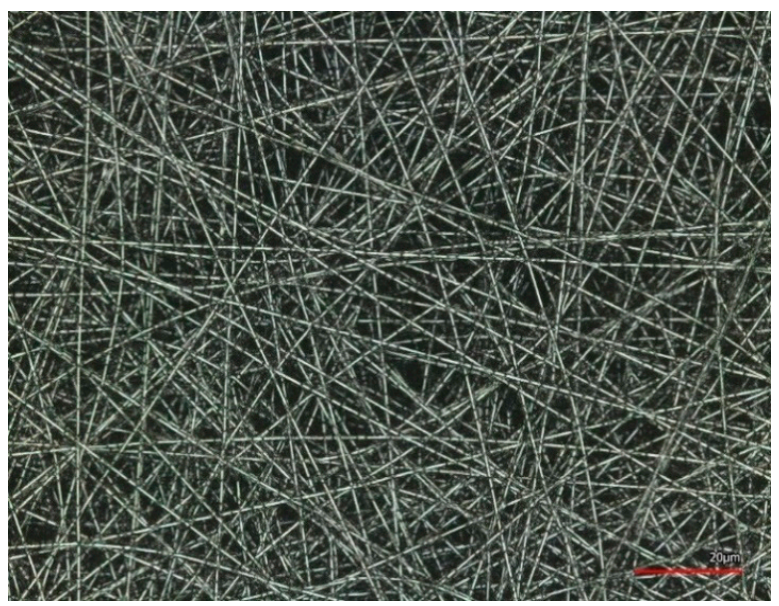

(b)

Figure 13. Confocal laser scanning microscope (CLSM) images of PAN/gelatin nanofiber mats on PJM object. PJM object is covered with nanofibers and is not visible: (a) sample-37, (b) sample-38. Scale bars indicate $20 \mu \mathrm{m}$.

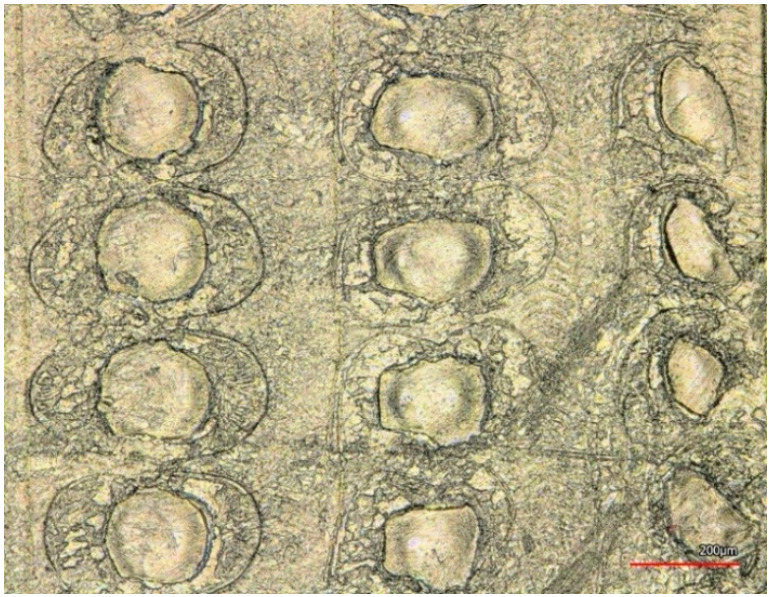

(a)

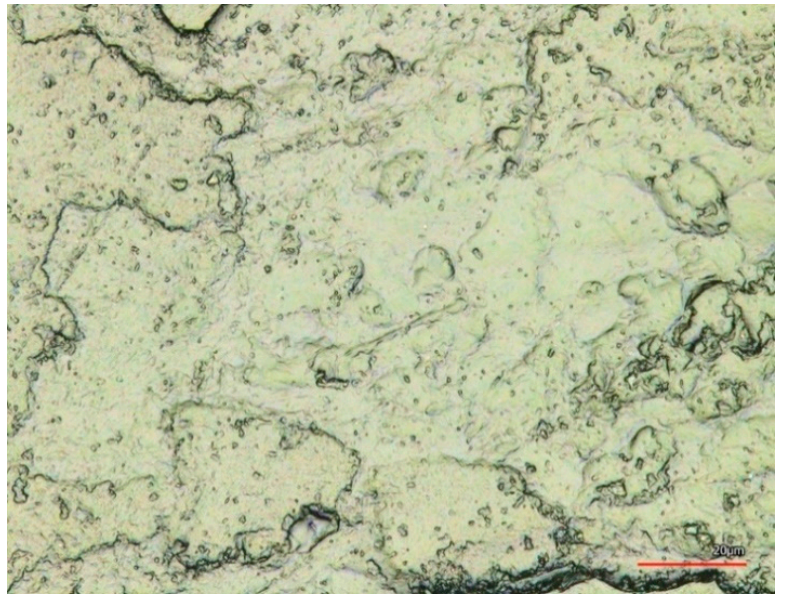

(b)

Figure 14. Confocal laser scanning microscope (CLSM) images of MED610 object, sample-29. Scale bars indicate: (a) $200 \mu \mathrm{m}$ (b) $20 \mu \mathrm{m}$. 
The surface morphology was analyzed using CLSM. Figure 9 shows CLSM images of the PAN nanofiber mats on PLA object. Here the nanofibers show mostly straight orientation with some tangled parts. Thicker nanofiber strands can also be observed. Figure 10 shows the 3D-printed side of PLA object. The PLA filament clearly shows distinct distances to other PLA filaments; the surface is not fused together and does not form a closed unit. In addition, the shape of the printed filaments is not linear and straight, but partly curved and not uniform. This could stem from discontinuous material release in the nozzle of the 3D printer, or from the temperature partially being too low in the upper layer of filament compared to the filament layer below.

Figure 11 shows CLSM images of the PAN/gelatin nanofiber mats on PLA object. In these samples, it is clearly visible that the fiber diameter has increased significantly compared to pure PAN nanofibers without gelatin (see Figures 9 and 15b). This parameter can be analyzed in terms of using the test results to build devices with filtering properties. That the addition of gelatin to PAN significantly increases the fiber diameter compared to pure PAN nanofibers, is an effect known from previous studies [37]. Figure 12 shows results for the 3D-printed side of PLA object. Compared to Figure 10, the filaments here form a closed unit with straight linear shapes and the layers of filament are close and fused to each other. Figure 13 shows CLSM images of the of PAN/gelatin nanofiber mats on MED610 object. Interestingly, at this point the nanofibers show much smaller diameters compared to the samples in Figure 11 (see Figure 15c), even though the nanofibers contain gelatin, which is known to increase the diameter of the nanofibers according to a previous study [37]. In this case, the nanofibers are on average much smaller and show strict straight alignment without tangles (see Figure 15c). It seems that the 3D material MED610 plays a major role here, in that the behavior of the nanofibers is completely different compared to that of the nanofibers with the same content of PAN and gelatin parts in Figure 11 that were electrospun on the PLA 3D object. This effect is unexpected and should be followed up. It should be noted that the material used for 3D printing has a clear influence on the filtering properties of the manufactured objects due to the filtering capabilities of nanofibers created during the electrospinning process. The production of fibers with a specific diameter affects the possibilities of filtration and materials separation. It should be stated that depending on the given 3D printing technology and materials, the control-process analysis of the electrospinning technology should be subjected to the appropriate selection of process parameters in order to obtain the composite structure and nanofiber diameters with a specific degree of filtration.

The diameter distributions of the PAN and PAN/gelatin nanofiber mats are presented in Figure 15.

The fiber diameter of PAN nanofibers on PLA resulted in a diameter distribution of $(241 \pm 84) \mathrm{nm}$. The PAN nanofibers with gelatin admixture resulted in a diameter distribution of $(528 \pm 157) \mathrm{nm}$ on PLA and $(388 \pm 178) \mathrm{nm}$ on MED610. Figure 14 shows the 3D printed side (MED610) with 200 and $20 \mu \mathrm{m}$ enlargement respectively. It can be seen that the resin MED610 is completely melted without visible defects and voids. Figures 10, 12 and 14 show the surface of samples viewed from the side of the printed material. With the FFF technology, the vertically distributed lines of PLA material are clearly visible, whereas in Figure 10 two successive, crossing layers of the material are visible. A completely different structure is presented for samples made of MED610 material and PJM technology. In Figure 14 there is no clear view of the layers, which is undoubtedly an advantage affecting the mechanical properties and the quality of the composites produced. In Figure 14a, uniformly distributed cylindrical geometric features (with a diameter of less than $200 \mu \mathrm{m}$ ) are visible, which correspond to the characteristics of the object building process using the PJM technology, where the visible traces correspond to thin sprayed drops of material. 


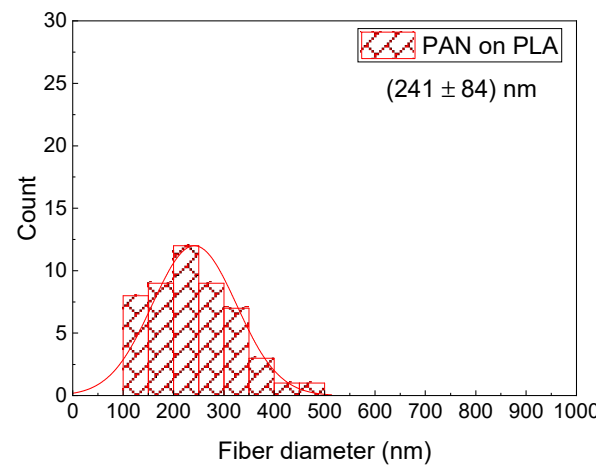

(a)

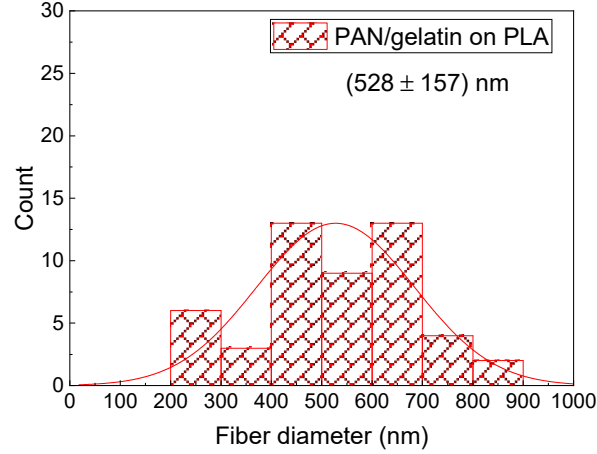

(b)

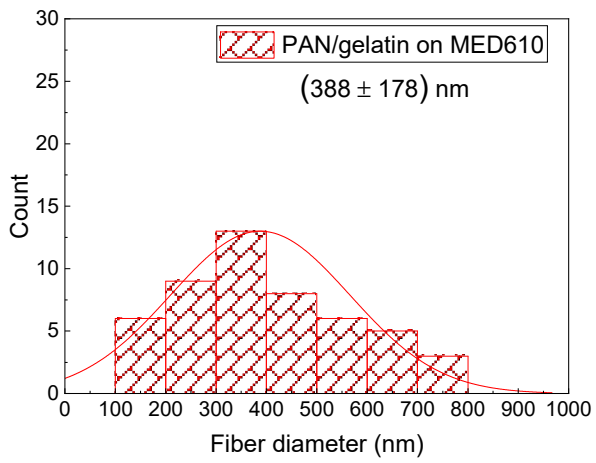

(c)

Figure 15. Diameter distribution of (a) PAN nanofiber mats on PLA object; (b) PAN/gelatin nanofiber on PLA object and (c) PAN/gelatin on MED610 object.

\subsection{Contact Angle Results}

The results of the contact angle measurements are presented in Tables 4 and 5 and in Figure 16. Tables 4 and 5 show the mean value of the contact angle measurement for 3D printed samples. The measurement of the contact angle of nanofiber mats was not possible because the droplet was immediately absorbed into the nanofiber mat due to the capillary effect.

Table 4. Contact angle measurement results for sample-18, PLA object.

\begin{tabular}{ccc}
\hline Calculated Feature & Image in Print Direction & $\begin{array}{c}\text { Image Perpendicular } \\
\text { to Print Direction }\end{array}$ \\
\hline $\begin{array}{c}\text { Mean values and standard } \\
\text { deviation of contact angle }\left({ }^{\circ}\right)\end{array}$ & $86.8( \pm 3.4)$ & $62.7( \pm 2.8)$ \\
\hline
\end{tabular}

Table 5. Contact angle measurement results for sample-29_PJM, MED610 material.

\begin{tabular}{ccc}
\hline Calculated Feature & Image in Print Direction & $\begin{array}{c}\text { Image Perpendicular } \\
\text { to Print Direction }\end{array}$ \\
\hline $\begin{array}{c}\text { Mean values and standard } \\
\text { deviation of contact angle }\left(^{\circ}\right)\end{array}$ & $54.7( \pm 5.5)$ & $45.2( \pm 4.0)$ \\
\hline
\end{tabular}




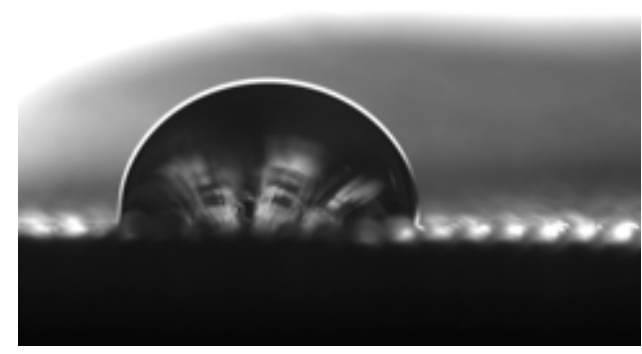

(a)

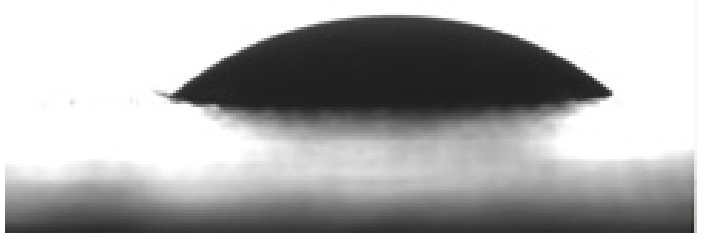

(b)

Figure 16. Contact angle measurement results (a) PLA object-sample 18, (b) MED610 objectsample 29.

The samples were examined in 'printing direction' and 'perpendicular to printing direction', because due to the 3D printing technology, the layers are built on top of each other, and the surface morphology as seen, for example, in Figure 11, has an impact on the contact angle measurement results (see Tables 4 and 5 and Figure 16). By analyzing the results of the contact angle measurement presented in Tables 3 and 4 for PLA and MED610 materials, it can be concluded that for two completely different production technologies there are clear differences in the values of the measured parameters. The highest values of $86.8^{\circ}$ on average were obtained for FFF and image in print direction technologies. In the case of PJM technology and MED610 material, the highest contact angle values are $54.7^{\circ}$ also for image in print direction. In the case of the PJM technology, a greater dispersion of the measurement results is clearly visible, amounting to SD-5.5 in the presented case image in 'print direction'. Based on the SD parameter, it can be concluded that the distribution of the results is relatively small and that the results are repeatable for both $3 \mathrm{D}$ printing technologies.

\section{Discussion}

The analysis of the results leads to the conclusion that 3D printed objects have an influence on the orientation of the nanofibers as well as on the nanofiber diameters, as shown by the results of this study. Generally, it is known that the addition of gelatin increases the nanofiber diameters compared to pure PAN nanofibers, which is observed for nanofiber mats electrospun on PLA. This conclusion has direct implications for the analysis of composites in terms of their filtration and medical applications. However, when the nanofibers are electrospun with gelatin on MED610, the morphology changes. In this case, the nanofibers are straighter and more oriented, and the fiber diameters decrease rapidly compared to PLA 3D printed objects. Moreover, with the increase in the diameter of nanofibers and their improper/unplanned arrangement, the filtration properties of the composite decrease due to the impossibility of filtration of small fractions of materials. When considering the engineering applications of the test results, it can be concluded that the MED610 material in combination with PAN/gelatin shows much better engineering properties (fibers' orientation), which may have influence into better quality control of the production of composite models with filtration properties. The analysis of the contact angle measurement results in real applications which allow us to conclude that the MED610 material will have a much better adhesion force. In addition, in the case of FFF technology and samples made on the basis of PLA, local densities and areas with lower fiber density are clearly visible, which can have a huge impact on the strength of the composite as can be seen in the Figures 9 and 10. It can be noticed, especially in Figure 9, Figure 11 (for PLA) and Figure 13 (for MED610), that the distribution of nanofibers in the areas of lower density generates gaps up to 1-2 $\mu \mathrm{m}$ in size, enabling the permeability of media such as liquids and gas/air in filtration applications. It seems that the next research effort should focus on an in-depth analysis of the sizes of gaps in order to determine the filtration capabilities of the composite and also on the distribution of the gaps in the composites that may also have 
an influence on the mechanical properties. In addition, the PLA object surface morphology clearly shows gaps in the layers, which in the case of the MED610 Object can hardly be discovered and the surface is not permeable.

Due to the structure of the samples, it is not possible to determine the adhesion force between the 3D printed part of the composite and the electrospinning technology. As the research results have shown [52,55], there is, however, a certain relationship between the contact angle and the adhesion force. As the results of previously conducted research work have shown, the contact angle has a significant impact on the adhesion force $[52,55]$. The results of the work showed that as the contact angle adhesion force increases, its value decreases. The contact angle results in the case of PLA material and FFF technology are characterized by the value for Image in print direction- $86.8^{\circ}$ (SD-3.4), and for Image perpendicular to print direction-62.7 (SD-2.8). Nevertheless, in the case of the PJM technology and the MED610 material, the mean value of the contact angle for the tested surface takes a much lower value, respectively: Image in print direction-54.7 $7^{\circ}$ (SD—5.5), and for Image perpendicular to print direction-45.2 (SD-4.0). Based on the results of the research presented in the literature, where the impact of the contact angle on adhesion force was analyzed in an indirect manner, it can be concluded that in the case of composites produced with the PJM and electrospinning adhesion force technology, it should show a higher value compared to the samples made with the 3D printing technology-FFF and electrospinning technology.

As numerous research studies show, the technological parameters of 3D printing affect the strength and quality of the surface; in the case of combining the printed objects with the electrospinning technology, however, there was no effect on the quality of the connection after the above-mentioned tests were carried out.

\section{Conclusions}

The article presents the results of research on composites manufactured with two 3D printing technologies: FFF from PLA material and PJM technology-MED610, and electrospinning technology from PAN and gelatin that also have medical uses. The analyzed parameters included print parameters such as the printing direction, layer thickness, and degree of filling (in FFF) with 3D printing material, and electrospinning process parameters such as electricity voltage, humidity, and chamber temperature. The analysis of the quality of the produced composite was based on the results of the surface morphology research using confocal laser scanning microscope (CLSM), fourier transform infrared spectroscopy (FTIR), and contact angle analysis.

It can also be concluded that a lower value of the contact angle will positively affect the adhesion force of the composite. In this study, it is shown that with variations of the applied 3D printing technology, such as FFF or PJM, the printing material, such as PLA and MED610, the polymers used for electrospinning for the production of nanofibers, such as PAN nanofibers or PAN combined with gelatin, versatile composites with different properties for defined medical applications can be produced. The influence of $3 \mathrm{D}$ printed materials on nanofibers has been observed here, allowing for the production of denser nanofibers with larger diameters or a denser matrix, etc. For example, depending on the defined filtration needs, smaller nanofibers with tighter interstitial spaces can filter out more particles, and a denser matrix of 3D printed layers can filter out coarser particles while protecting the sensitive nanofiber layer from mechanical influences. These variations of composites with denser or more flexible nanofibers are diverse. There is a need for further research in this area.

It seems that the use of both composite materials characterized by a high degree of biocompatibility, confirmed by ISO standards and preliminary analyzes of the structure of nanofibers and their orientation, dimensions, allows us to conclude that by selecting 3D printing technology and electrospinnning materials, we are able to control the production process of composites of a specific quality in order to ensure appropriate the desired degree of filtration and the biomedical application results from the fact that the analyzed 
biomedical materials allow for the creation of durable models with desirable properties, in this case filtration.

In conclusion, compare these two methodology of manufacturing composite it could be stated that the PLA and MED610 materials have an influence on the nanofiber diameter in different way. The CLSM images look different from the surface morphology of the 3D printed objects made of PLA and MED610. In the case of PLA, the spaces between the individual strands of the PLA material are clearly visible. There is a denser surface morphology of MED610 compared to PLA. This means that, depending on the defined purpose, with variations of materials, different surface morphologies can be produced, which is advantageous for defined filter applications.

Author Contributions: Conceptualization, T.K.; methodology, T.K.; software, M.T., L.S. and A.M.; validation, T.K.; formal analysis, T.K.; investigation, L.S., M.T., A.M. and T.K.; resources, T.K. and A.M.; data curation, L.S., M.T., A.M. and T.K.; writing-original draft preparation, T.K., A.M., M.T. and L.S.; writing-review and editing, T.K., A.M., M.T. and L.S.; visualization, T.K.; supervision, T.K. and L.S.; project administration, T.K.; funding acquisition, T.K. All authors have read and agreed to the published version of the manuscript.

Funding: This research was funded by National Science Center of Poland under the Miniatura 4, grant number 2020/04/X/ST5/00057 entitled: Analysis of polymer composites produced by 3D printing and electrospinning technologies in the applications of filtering devices.

Institutional Review Board Statement: Not applicable.

Informed Consent Statement: Not applicable.

Data Availability Statement: The data created in this study are fully depicted in the article.

Acknowledgments: The authors acknowledge personal funding from the internal PhD funds of Bielefeld University of Applied Sciences, Erasmus+ and the internal funds for female students in STEM programs at Bielefeld University of Applied Sciences.

Conflicts of Interest: The authors declare no conflict of interest.

\section{References}

1. Adamczak, S.; Zmarzly, P.; Kozior, T.; Gogolewski, D. Analysis of The Dimensional Accuracy of Casting Models Manufactured by Fused Deposition Modeling Technology. In Proceedings of the Engineering Mechanics 2017, Svratka, Czech Republic, 15-18 May 2017.

2. Kozior, T.; Bochnia, J.; Zmarzły, P.; Gogolewski, D.; Mathia, T.G. Waviness of freeform surface characterizations from austenitic stainless steel (316L) manufactured by 3D printing-selective laser melting (SLM) technology. Materials 2020, 13, 4372. [CrossRef]

3. Varela, L.; Araújo, A.; Ávila, P.; Castro, H.; Putnik, G. Evaluation of the relation between lean manufacturing, industry 4.0, and sustainability. Sustainability 2019, 11, 1439. [CrossRef]

4. Kozior, T. The influence of selected selective laser sintering technology process parameters on stress relaxation, Mass of models, and their surface texture quality. 3D Print. Addit. Manuf. 2020, 7, 126-138. [CrossRef]

5. Madej, M.; Styp-Rekowski, M.; Wieciński, P.; Płociński, T.; Ozimina, D.; Kurzydłowski, K.; Matuszewski, M. Properties of diamond-like carbon coatings deposited on cocrmo alloys. Trans. Famena 2015, 39, 79-88.

6. Ozimina, D.; Madej, M.; Kałdoński, T. The wear resistance of HVOF sprayed composite coatings. Tribol. Lett. 2011, 41, 103-111. [CrossRef]

7. Madej, M.; Ozimina, D. Electroless Ni-P-Al $\mathrm{Al}_{2}$ composite coatings. Kov. Mater. 2006, 44, 291-296.

8. Okolo, C.; Rafique, R.; Iqbal, S.S.; Saharudin, M.S.; Inam, F. Carbon nanotube reinforced high density polyethylene materials for offshore sheathing applications. Molecules 2020, 25, 2960. [CrossRef] [PubMed]

9. Bochnia, J.; Blasiak, M.; Kozior, T. Tensile strength analysis of thin-walled polymer glass fiber reinforced samples manufactured by 3D printing technology. Polymers 2020, 12, 2783. [CrossRef]

10. Saharudin, M.S.; Hajnys, J.; Kozior, T.; Gogolewski, D.; Zmarzły, P. Quality of surface texture and mechanical properties of PLA and PA-based material reinforced with carbon fibers manufactured by FDM and CFF 3D printing technologies. Polymers 2021, 13, 1671. [CrossRef]

11. Mousapour, M.; Salmi, M.; Klemettinen, L.; Partanen, J. Feasibility study of producing multi-metal parts by Fused Filament Fabrication (FFF) technique. J. Manuf. Process. 2021, 67, 438-446. [CrossRef]

12. Dziegielewski, W.; Kowalczyk, J.; Kulczycki, A.; Madej, M.; Ozimina, D. Tribochemical interactions between carbon nanotubes and ZDDP antiwear additive during tribofilm formation on uncoated and DLC-Coated steel. Materials 2020, 12, 2409. [CrossRef] 
13. Kozior, T.; Kundera, C. Viscoelastic properties of cell structures manufactured using a photo-curable additive technology-PJM. Polymers 2021, 13, 1895. [CrossRef]

14. Kundera, C.; Martsynkowskyy, V.; Gudkov, S.; Kozior, T. Effect of rheological parameters of elastomeric ring materials on dynamic of face seals. Procedia Eng. 2017, 177, 307-313. [CrossRef]

15. Kozior, T.; Mamun, A.; Trabelsi, M.; Wortmann, M.; Sabantina, L.; Ehrmann, A. Electrospinning on 3D printed polymers for mechanically stabilized filter composites. Polymers 2019, 11, 2034. [CrossRef]

16. Kozior, T.; Trabelsi, M.; Mamun, A.; Sabantina, L.; Ehrmann, A. Stabilization of electrospun nanofiber mats used for filters by 3D printing. Polymers 2019, 11, 1618. [CrossRef] [PubMed]

17. Martens, Y.; Ehrmann, A. Composites of 3D-Printed Polymers and Textile Fabrics. In Proceedings of the IOP Conference Series: Materials Science and Engineering, Xiamen, China, 20-22 October 2017.

18. Unger, L.; Scheideler, M.; Meyer, P.; Harland, J.; Görzen, A.; Wortmann, M.; Dreyer, A.; Ehrmann, A. Increasing adhesion of 3D printing on textile fabrics by polymer coating. Tekstilec 2018, 61, 265-271. [CrossRef]

19. Upadhyay, M.; Sivarupan, T.; El Mansori, M. 3D printing for rapid sand casting-A review. J. Manuf. Process. 2017, 29, 211-220. [CrossRef]

20. Hlinka, J.; Kraus, M.; Hajnys, J.; Pagac, M.; Petru, J.; Brytan, Z.; Tanski, T. Complex corrosion properties of aisi 316L steel prepared by 3D printing technology for possible implant applications. Materials 2020, 13, 1527. [CrossRef]

21. Budzik, G.; Przeszlowski, L.; Wieczorowski, M.; Rzucidlo, A.; Gapinski, B.; Krolczyk, G. Analysis of 3D printing parameters of gears for hybrid manufacturing. AIP Conf. Proc. 2018, 1960, 140005. [CrossRef]

22. Kozior, T.; Mamun, A.; Trabelsi, M.; Sabantina, L.; Ehrmann, A. Quality of the surface texture and mechanical properties of FDM printed samples after thermal and chemical treatment. Stroj. Vestn./J. Mech. Eng. 2020, 66, 105-113. [CrossRef]

23. Chalgham, A.; Ehrmann, A.; Wickenkamp, I. Mechanical properties of fdm printed pla parts before and after thermal treatment. Polymers 2021, 13, 1239. [CrossRef] [PubMed]

24. Mamun, A.; Blachowicz, T.; Sabantina, L. Electrospun Nanofiber Mats for Filtering Applications-Technology, Structure and Materials. Polymers 2021, 13, 1368. [CrossRef] [PubMed]

25. Kozior, T.; Bochnia, J. The influence of printing orientation on surface texture parameters in powder bed fusion technology with 316L steel. Micromachines 2020, 11, 639. [CrossRef] [PubMed]

26. Bochnia, J.; Blasiak, S. Fractional relaxation model of materials obtained with selective laser sintering technology. Rapid Prototyp. J. 2019, 25, 76-86. [CrossRef]

27. Hanon, M.M.; Marczis, R.; Zsidai, L. Influence of the 3D printing process settings on tensile strength of PLA and HT-PLA. Period. Polytech. Mech. Eng. 2021, 65, 38-46. [CrossRef]

28. Ehrmann, G.; Ehrmann, A. Pressure orientation-dependent recovery of 3D-printed PLA objects with varying infill degree. Polymers 2021, 13, 1275. [CrossRef]

29. Ehrmann, G.; Ehrmann, A. Investigation of the shape-memory properties of 3D printed pla structures with different infills. Polymers 2021, 13, 164. [CrossRef] [PubMed]

30. Kozior, T.; Kundera, C. Surface texture of models manufactured by FDM technology. In Proceedings of the AIP Conference Proceedings, Maharashtra, India, 5-6 July 2018.

31. Thompson, A.; Maskery, I.; Leach, R.K. X-ray computed tomography for additive manufacturing: A review. Meas. Sci. Technol. 2016, 27, 072001. [CrossRef]

32. Wortmann, M.; Frese, N.; Sabantina, L.; Petkau, R.; Kinzel, F.; Gölzhäuser, A.; Moritzer, E.; Hüsgen, B.; Ehrmann, A. New polymers for needleless electrospinning from low-toxic solvents. Nanomaterials 2019, 9, 52. [CrossRef] [PubMed]

33. Sabantina, L.; Klöcker, M.; Wortmann, M.; Mirasol, J.R.; Cordero, T.; Moritzer, E.; Finsterbusch, K.; Ehrmann, A. Stabilization of polyacrylonitrile nanofiber mats obtained by needleless electrospinning using dimethyl sulfoxide as solvent. J. Ind. Text. 2020, 20, 224-239. [CrossRef]

34. Wehlage, D.; Blattner, H.; Sabantina, L.; Böttjer, R.; Grothe, T.; Rattenholl, A.; Gudermann, F.; Lütkemeyer, D.; Ehrmann, A. Sterilization of pan/gelatine nanofibrous mats for cell growth. Tekstilec 2019, 62, 78-88. [CrossRef]

35. Wehlage, D.; Blattner, H.; Mamun, A.; Kutzli, I.; Diestelhorst, E.; Rattenholl, A.; Gudermann, F.; Lütkemeyer, D.; Ehrmann, A. Cell growth on electrospun nanofiber mats from polyacrylonitrile (PAN) blends. AIMS Bioeng. 2020, 7, 43-54. [CrossRef]

36. Trabelsi, M.; Mamun, A.; Klöcker, M.; Sabantina, L. Investigation of metallic nanoparticle distribution in PAN/magnetic nanocomposites fabricated with needleless electrospinning technique. Commun. Dev. Assem. Text. Prod. 2021, 2, 8-17. [CrossRef]

37. Sabantina, L.; Wehlage, D.; Klöcker, M.; Mamun, A.; Grothe, T.; García-Mateos, F.J.; Rodríguez-Mirasol, J.; Cordero, T.; Finsterbusch, K.; Ehrmann, A. Stabilization of electrospun PAN/gelatin nanofiber mats for carbonization. J. Nanomater. 2018, 2018, 61310. [CrossRef]

38. Grothe, T.; Sabantina, L.; Klöcker, M.; Junger, I.; Döpke, C.; Ehrmann, A. Wet relaxation of electrospun nanofiber mats. Technologies 2019, 7, 23. [CrossRef]

39. Fokin, N.; Grothe, T.; Mamun, A.; Trabelsi, M.; Klöcker, M.; Sabantina, L.; Döpke, C.; Blachowicz, T.; Hütten, A.; Ehrmann, A. Magnetic properties of electrospun magnetic nanofiber mats after stabilization and carbonization. Materials 2020, 13, 1552. [CrossRef] 
40. Sabantina, L.; Böttjer, R.; Wehlage, D.; Grothe, T.; Klöcker, M.; García-Mateos, F.J.; Rodríguez-Mirasol, J.; Cordero, T.; Ehrmann, A. Morphological study of stabilization and carbonization of polyacrylonitrile/ $\mathrm{TiO}_{2}$ nanofiber mats. J. Eng. Fiber. Fabr. 2019, 14, 1-8. [CrossRef]

41. Yusof, M.R.; Shamsudin, R.; Zakaria, S.; Hamid, M.A.A.; Yalcinkaya, F.; Abdullah, Y.; Yacob, N. Electron-beam irradiation of the PLLA/CMS/ $\beta$-TCP composite nanofibers obtained by electrospinning. Polymers 2020, 12, 1593. [CrossRef]

42. Kozior, T.; Blachowicz, T.; Ehrmann, A. Adhesion of three-dimensional printing on textile fabrics: Inspiration from and for other research areas. J. Eng. Fiber. Fabr. 2020, 15, 1-6. [CrossRef]

43. Greiner, A.; Wendorff, J.H. Electrospinning: A fascinating method for the preparation of ultrathin fibers. Angew. Chemie Int. Ed. 2007, 46, 5670-5703. [CrossRef] [PubMed]

44. Makerbot FDM Technology. Available online: https://www.makerbot.com/3d-printers/method/tech-specs/ (accessed on 27 November 2021).

45. Stratasys Biocompatible Clear MED610-Sheet Data. Available online: https://www.sys-uk.com/wp-content/uploads/2016/01/ MSDS-Clear-Bio-Compatible-MED610-English-US-1.pdf (accessed on 27 November 2021).

46. ISO 10993. Biological evaluation of medical devices. In Biological Evaluation of Medical Devices; ISO: Geneva, Switzerland, 2009.

47. GTMDB05 Biological Reactivity Tests, In Vivo. In Phyllanthin, United States Pharmacopeia; USP: Rockville, MA, USA, 2018.

48. PLA Structural Formula. Available online: https://omnexus.specialchem.com/selection-guide/polylactide-pla-bioplastic (accessed on 27 November 2021).

49. Molnár, K.; Szolnoki, B.; Toldy, A.; Vas, L.M. Thermochemical stabilization and analysis of continuously electrospun nanofibers. J. Therm. Anal. Calorim. 2014, 117, 1123-1135. [CrossRef]

50. Al-Saidi, G.S.; Al-Alawi, A.; Rahman, M.S.; Guizani, N. Fourier transform infrared (FTIR) spectroscopic study of extracted gelatin from shaari (Lithrinus microdon) skin: Effects of extraction conditions. Int. Food Res. J. 2012, 19, 1167-1173.

51. Chieng, B.W.; Ibrahim, N.A.; Yunus, W.M.Z.W.; Hussein, M.Z.; Then, Y.Y.; Loo, Y.Y. Effects of graphene nanoplatelets and reduced graphene oxide on poly(lactic acid) and plasticized poly(lactic acid): A comparative study. Polymers 2014, 6, 2232-2246. [CrossRef]

52. Kozior, T.; Döpke, C.; Grimmelsmann, N.; Juhász Junger, I.; Ehrmann, A. Influence of fabric pretreatment on adhesion of three-dimensional printed material on textile substrates. Adv. Mech. Eng. 2018, 10, 1-8. [CrossRef]

53. Sato, S.; Swihart, M.T. Propionic-acid-terminated silicon nanoparticles: Synthesis and optical characterization. Chem. Mater. 2006, 18, 4083-4088. [CrossRef]

54. Stratasys. PolyJet 3D Printers Systems and Materials Overview; Stratasys: Rehovot, Israel, 2018.

55. Korger, M.; Bergschneider, J.; Lutz, M.; Mahltig, B.; Finsterbusch, K.; Rabe, M. Possible applications of 3D printing technology on textile substrates. IOP Conf. Ser. Mater. Sci. Eng. 2016, 141, 01201. [CrossRef] 